\title{
F-Actin Distribution Changes Provoked by Acetaminophen in the Proximal Tubule in Kidney of Adult Male Rat
}

\author{
Fernando Jaramillo-Juárez ${ }^{1}$, Jose Roberto Macías-Pérez ${ }^{2}$, Ma. Consolación \\ Martínez-Saldaña ${ }^{2}$, Francisco Javier Avelar-González ${ }^{1}$, Víctor Manuel Loera-Muro, \\ Edgar Eduardo Hernández-Cuéllar², Francisco Jaramillo², \\ Higinio Manuel González Reynaga ${ }^{2}$, Alma Lilian Guerrero-Barrera ${ }^{2 *}$ \\ ${ }^{1}$ Departamento de Fisiologia y Farmacologia, Centro de Ciencias Basicas, Universidad Autonoma de \\ Aguascalientes, Aguascalientes, Mexico \\ ${ }^{2}$ Departamento de Morfologia, Centro de Ciencias Basicas, Universidad Autonoma de Aguascalientes, \\ Aguascalientes, Mexico \\ Email: "alguerre@correo.uaa.mx
}

Received 18 May 2016; accepted 9 July 2016; published 12 July 2016

Copyright (C) 2016 by authors and Scientific Research Publishing Inc. This work is licensed under the Creative Commons Attribution International License (CC BY). http://creativecommons.org/licenses/by/4.0/

(c) (i) Open Access

\begin{abstract}
Acetaminophen is a drug used to treat many conditions as headache, muscle aches, arthritis, backache, toothache, and fever between others, but collateral effects of this drug are not well known yet. Here is tested its effect on proximal tubule epithelium. Acetaminophen (APAP) at doses of 200, 500, 1000 and $1500 \mathrm{mg} / \mathrm{Kg}$ i.p. caused cell damage and changes in F-actin distribution in the proximal tubule of male Wistar rats. After 48 hours of treatment, the proximal tubule epithelium showed tumefaction and necrosis. Dose of $200 \mathrm{mg} / \mathrm{kg}$ decreased the F-actin and was observed a structure in patches in the basal cytoplasm of epithelial cells of the proximal tubule. This effect was increased depending on the administered dose. Dose of $1000 \mathrm{mg} / \mathrm{kg}$ produced the highest histological damage and changes in the actin cytoskeleton. Results of this study suggested that nephrotoxic damage produced by high doses of APAP included breakdown of cytoskeleton in proximal tubule epithelium.
\end{abstract}

\section{Keywords}

Acetaminophen, Cytoskeleton, Proximal Tubule, Kidney Damage

\footnotetext{
"Corresponding author.
} 


\section{Introduction}

Acetaminophen (APAP) is one of the analgesics and antipyretics most widely used in clinical and home worldwide due to its high efficacy, low cost and because it can be bought over-the-counter. This drug can cause intoxication with significant morbi-mortality including fulminant hepatic necrosis and acute renal failure [1] [2]. APAP nephrotoxicity includes cell necrosis induced by in situ bioactivation attributable to CYP450 isoforms, particularly 2E1 and 1A2 [3] [4]. Electrophilic compounds generated by CYP450 (N-acetyl-p-benzo-quinone imine) disrupt the cellular antioxidants mechanisms and can react with subcellular structures; this promotes the generation of reactive oxygen species and induces lipid peroxidation of cell membranes. This process alters the structure and permeability of the cell membrane, and increases the intracellular calcium concentration and active enzymes such as endonucleases, phospholipases and proteases which degrade cytoskeletal proteins and carry out the final cytolytic process [5] [6].

Nephrotoxic damage is characterized by decreased renal cells, leading to acute renal failure syndrome, which can progressively cause chronic renal failure associated to fibrosis. Also it has been observed loss of tubular cell, death of renal tubular epithelium can be induced by endogenous lethal factors such as cytokines, and exogenous factors such as cyclosporine A (CsA), aflatoxin B1, lead and APAP [4] [7]-[9]. It has been reported that high doses of APAP produces tubular epithelial cells apoptosis [10]. It is pertinent to note that the proximal convoluted tubule cells have microvilli on the apical membrane (brush border), which increases the reabsorption surface of water and solutes filtered in the renal glomeruli [11] [12]. Microvilli structure is mainly formed by filamentous actin (F-actin) which interacts with transmembrane proteins such as carrier molecules involved in the processes of reabsorption and tubular secretion [13].

Considering the importance of the kidneys in maintaining body homeostasis and the renal failure caused by APAP, the aim of this study is to analyze the toxic action of increasing doses of this drug on the cell structure and cell cytoskeleton on proximal convoluted tubule.

\section{Materials and Methods}

\subsection{Experimental Protocols}

Adult male Wistar rats were used. Animals were placed in clean cages and had free access to water and rodent chow. Care and handling of animals was performed according to international standards (Guiding Principles in the Use of Animals in Toxicology). Four experimental groups and a control group were integrated $(\mathrm{N}=3$ rats/group). Sixty $\mathrm{mL}$ of a mixture of physiological saline solution (PSS) and propylene glycol (PG, Sigma Chem Co.) was prepared in ratio 7/5 v/v (35 mL PG and PSS $25 \mathrm{~mL}$ ), $12 \mathrm{~mL}$ of this solution were placed in flasks and to each flask was added APAP (Sigma Chem Co.) in amounts enough to get the final concentrations that allowed administration at doses of 200, 500, 1000 and $1500 \mathrm{mg} / \mathrm{kg}$ (each rat received $3 \mathrm{~mL}$ approx. of the corresponding APAP solution, intraperitoneally). Control group was treated only with vehicle solution. In order to establish the general health conditions, rats were monitored for 48 hours after treatment with APAP.

\subsection{Perfusion Fixation}

After receiving the respective treatments, animals were anesthetized with $25 \mathrm{mg} / \mathrm{kg}$ i.p. of pentobarbital sodium (Aranda), heart was exposed by surgically opening of the chest and, using an infusion pump (Kd Scientific) to remove residual blood, the left ventricle was perfused with $120 \mathrm{~mL}$ of phosphate buffer solution (pH 7.4) containing heparin (1000 U) and procaine (1 g/L, Sigma Chem Co.). Subsequently fixative was administered, a 10\% formaldehyde (JT Baker) solution pH 7.4 [14]. Once perfusion was finished, kidney was surgically removed; a sagittal section was placed in a fixative solution of glutaraldehyde (JT Baker) and 0.05\% paraformaldehyde (JT Baker) at 4\%, (pH 7.4). Kidney was processed and embedded in paraffin, according to Laboratory Methods in Histotechnology from Armed Forces Institute of Pathology [15]. Sections were made in thickness of $5 \mu \mathrm{M}$ and were stained with hematoxylin and eosin. Preparations were observed under bright field microscope (Zeiss Axioskop 40). Image capture was performed using the System Image Pro Plus (Media Cybernetics).

\subsection{Histological analysis}

Histological evaluation was qualitative. Five fields were observed with 40X objective. Fields were randomly se- 
lected and were identified proximal tubule cross-sections. It was determined the presence of normal and altered cells in the proximal tubule epithelium. For identification of normal cells, they were considered cell volume, acidophilic cytoplasm pattern, nuclear volume and basophilic pattern, presence of a brush border and characteristics of the basement membrane. Structural alterations according to the kind of cell injury induced by APAP, were determined based on protocols of structural and functional pathology, in which are established the features of cell tumefaction or hydropic degeneration and cell death by necrosis.

\subsection{Cytoskeleton Study}

Rats were anesthetized and perfused, then kidney samples were obtained and frozen in presence of Tissue Tek OCT (Qiagen). $10 \mu \mathrm{M}$ thick frozen sections were obtained and F-actin recognition was performed with Alexa 594 phalloidin (Molecular Probes) [16]. Cells were permeabilized with methanol (15 minutes) (JT Baker) then fixed in 3.7\% (v/v) formaldehyde (JT Baker) in PBS pH 7.4 for 20 minutes and washed 3 times with PBS pH 7.4. Then sections were incubated with Alexa Fluor ${ }^{\circledR} 594$ phalloidin $(500 \mathrm{ng} / \mathrm{mL})$ for 1 hour $37^{\circ} \mathrm{C}$, washed 3 times with PBS pH 7.4 and once with distilled water. Samples were mounted with Prolong Gold (Molecular Probes). Histological samples were observed by fluorescence microscope Zeiss Axioscope 40. Images capture was performed using the System Image Pro Plus (Media Cybernetics).

\section{Results}

After APAP administration, rats were monitored for 48 hours. According to the dose, mortality was as follows: 1) $100 \%$ of the animals that received $1500 \mathrm{mg} / \mathrm{kg}$, and 2) $33.3 \%$ in rats that received $1000 \mathrm{mg} / \mathrm{kg}$ of the drug. In control group and groups receiving 500 and $200 \mathrm{mg} / \mathrm{kg}$ of APAP survived $100 \%$ of the rats. Histological examination of the renal cortex of rats in the control group showed normal organization and structure in the proximal tubular epithelium (Figure 1(a)). Structured actin cytoskeleton (F-actin) labeled with Alexa 594 phalloidin showed a distribution throughout cytoplasm of proximal cells, and more structured regions observed as brighter spots and concentrated toward basal side on epithelial cells. These points may represent the presence of hemidesmosomes in which is anchored the actin microfilaments through desmin which constitutes it [17] [18]. Distal tubules also present a structured actin cytoskeleton covering the entire cytoplasm, with a higher concentration at basal side of epithelial cells, which coincides with the presence of hemidesmosomes (Figure 1(b)). Also observed structuring of actin cytoskeleton at the apical cell membrane, related with microvilli that provide a larger surface for transport of solutes from tubule lumen to blood vessels [13]. Histological evaluation of renal cortex of rats treated with APAP showed proximal tubular epithelial injury. Normal cells were observed in these epithelia, with tumefaction and necrotic features. Cell with tumefaction presents increases in cell volume, vacuolated cytoplasm, loss of brush border, and apparently normal nucleus (Figure 2). Necrotic cells showed increased acidophilic cytoplasm, loss of brush border, nuclear changes, resembles pyknosis-like and detachment of basement membrane (Figure 2(a) and Figure 3(a)).
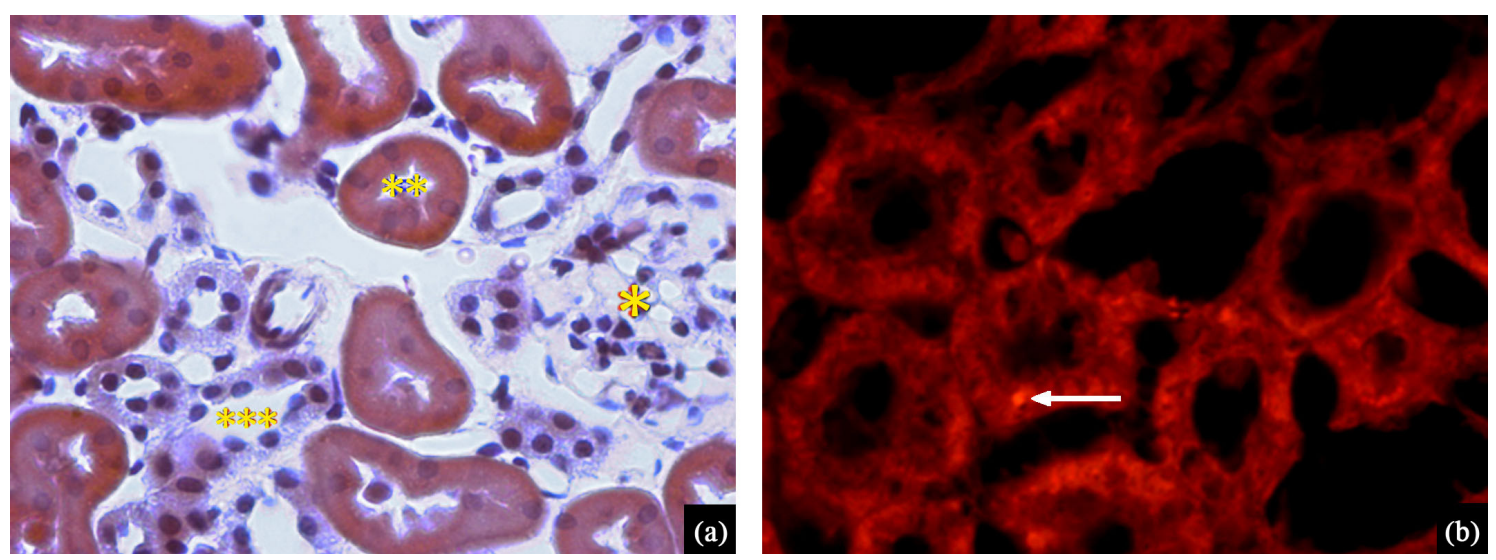

Figure 1. (a) H/E staining of control rat renal cortex, original objective 40X. Show a glomerulus $(*)$, proximal (**) and distal $(* * *)$ tubules. (b) F-actin labeled by Alexa 594 phalloidin in Control rat renal cortex, original objective 40X. Show proximal $(* *)$ and distal $(* * *)$ tubules, arrow points to the highest F-actin structure. 

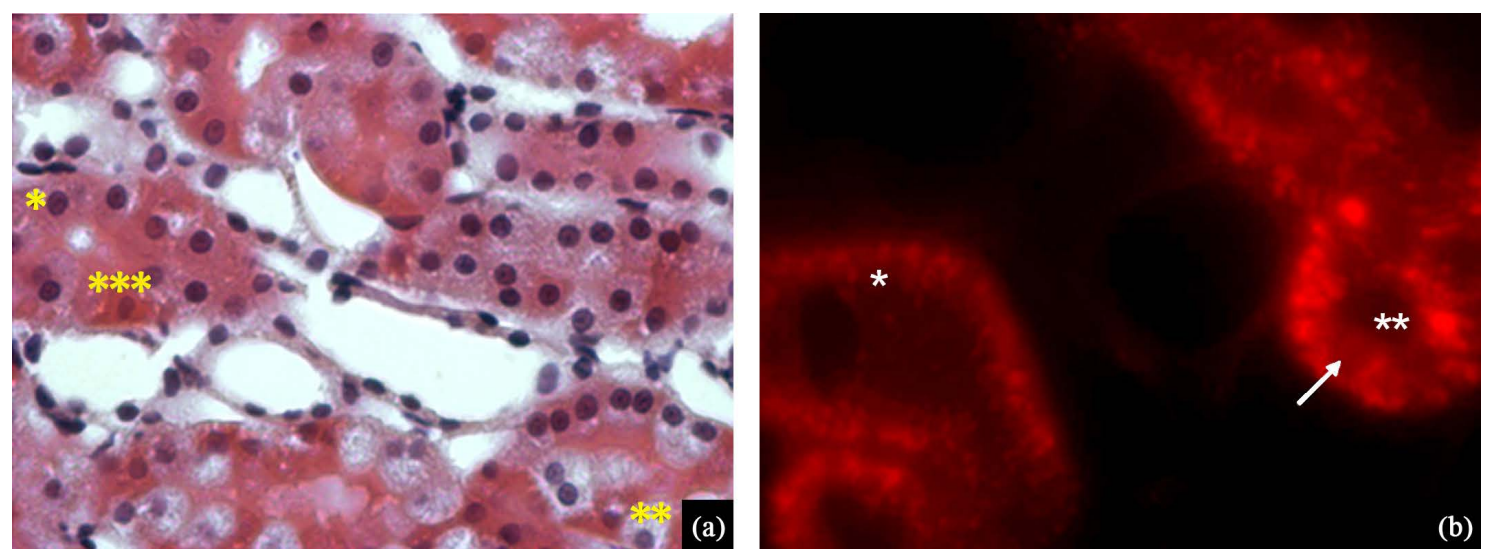

Figure 2. (a) H/E staining of rat renal cortex treated with $200 \mathrm{mg} / \mathrm{kg}$ of APAP, original objective 40X. The proximal tubule epithelium shows normal cells (*), with tumefaction $\left(^{* *}\right)$ and necrosis (***). (b) Renal cortex of rat treated with $200 \mathrm{mg} / \mathrm{kg}$ of APAP labeled with Alexa 594 phalloidin, original objective 40X. The proximal tubule epithelium shows some decrease in structured actin $(*)$, other cells retain the distribution observed in the control $\left({ }^{* *}\right)$. Arrow indicates a swollen cell, where is lost the F-actin structure.
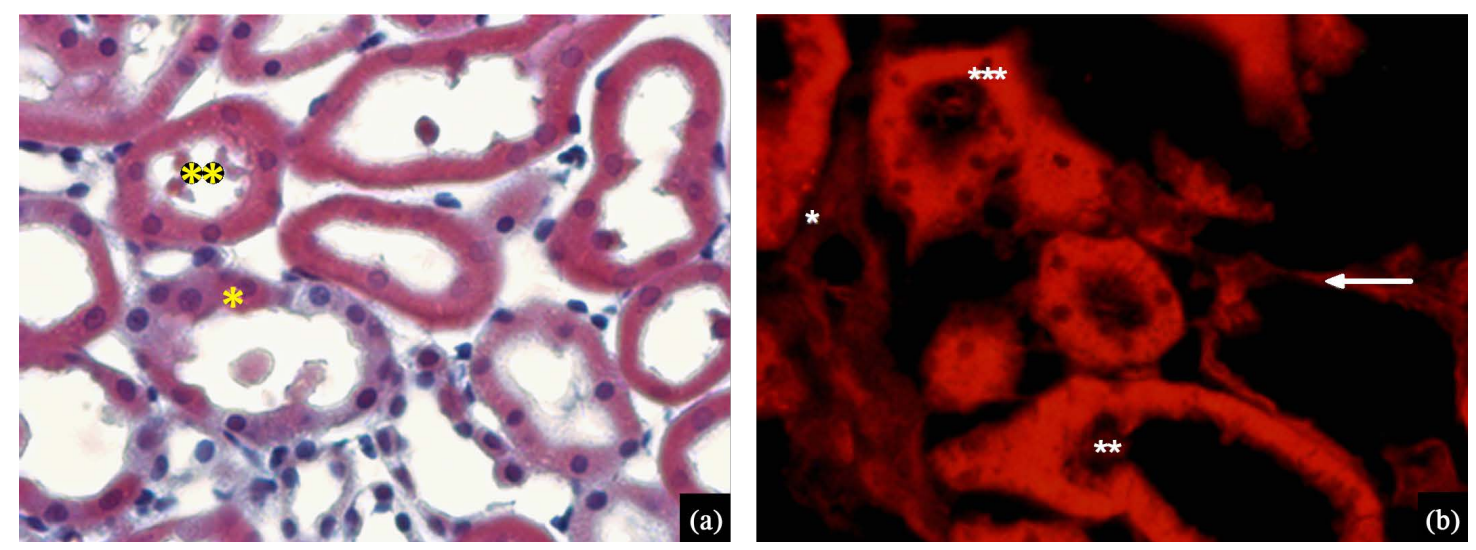

Figure 3. (a) H/E staining of renal cortex of rat treated with $500 \mathrm{mg} / \mathrm{kg}$ of APAP, original objective 40X. Picture shows necrotic tubular cells (*) and detached into the tubular lumen (**). (b). Rat renal cortex treated with $500 \mathrm{mg} / \mathrm{kg}$ of APAP, labeled with Alexa 594 phalloidin, original objective 40X. Picture shows necrotic tubular cells (*) with actin disruption, detached cells in the tubular lumen (**) and proximal tubules with high amount of F-actin and changes on its distribution (***). Arrow points to a distal tubule with no change in the distribution of F-actin with respect to control.

The kind of damage and the number of damaged cells increased depending on dose of APAP. Proximal tubule epithelium in renal cortex of rats treated with $200 \mathrm{mg} / \mathrm{kg}$ of APAP, showed abundant cells with tumefaction and few necrotic cells (Figure 2(a)). In addition, there were evident changes in cytoskeleton and proximal tubules were found with evident decrease of F-actin, with concentrated points toward the basal side of epithelial cells (Figure 2(b)), although also there were cells that had the same distribution of F-actin as proximal cells of control rats. It is important to highlight that the cells with tumefaction practically lost F-actin structuration (Figure 2(b)). Regarding the above, in rats treated with APAP, the observed F-actin patches in the base of epithelial cells may be hemidesmosomes associated in their intermediate filaments to structured actin [17] [18], more studies are necessary in order to clarify it.

In the proximal epithelium of rats treated with $500 \mathrm{mg} / \mathrm{kg}$ of APAP cells were observed with tumefaction and an increased number of necrotic cells with detachment of basement membrane (Figure 3(a)). With this treatment, F-actin cytoskeleton showed a clear decrease in necrotic epithelial cells, also were observed detached phalloidin labeled cells and proximal tubules with increased phalloidin labeling without basal distribution of F-actin (Figure 3(b)) as in proximal epithelium of control rats (Figure 1(b)). In Figure 3(b) is shown a distal tubule with no apparent change in F-actin distribution.

Finally, the proximal tubular epithelium of rats treated with $1000 \mathrm{mg} / \mathrm{kg}$ of APAP showed, in some areas of 
the renal cortex, cells with tumefaction and higher amount of necrotic cells with basement membrane detachment, this lesion is described as acute tubular necrosis. Tubular cell loss is evident by their presence in the tubular lumen and for the sites where began the epithelial regeneration process (Figure 4). With this treatment, F-actin cytoskeleton of cells in regeneration showed a distribution similar to that cells from control rats, with a patchy distribution more abundant in the basal side of epithelial cells (Figure 4(b)), while necrotic cells showed a greater dispersion of the F-actin mark (Figure 4(b)).

\section{Discussion}

In studies by transmission electron microscopy, it was found that, lead chronic treatment, produces rearrangements on intercellular junctions of rat renal proximal tubules, and there are numerous desmosomes junctions like electron-dense patches, localized to the apical side on epithelial cells, thereby increasing the sealing of collapsing tubules [19]. Furthermore, Newsome (2010) describe that APAP, in high doses in pigs induces severe tubular damage and vacuolization of cortical tubular epithelium. Moreover, the results obtained in this study with high doses of APAP are consistent with data of other researchers about chronic damage caused by lead in the proximal tubules of rat kidneys, which alters the apical membrane, brush border disappears and collapses of tubule lumen [20]. The mortality due to APAP in this study is in agreement with reports of different investigators. Indeed, APAP overdose causes acute liver failure (centrilobular necrosis) and nephrotoxic damage, causing high mortality in humans and in laboratory animals [21]-[23]. It is important to highlight the fact that APAP is a drug which at therapeutic plasma concentrations, reduces renal oxidative damage, improves function and reduces kidney damage [23] [24]. However, has been also reported that excess intake of this drug induce acute interstitial nephritis characterized by $\mathrm{CD}^{+} \mathrm{T}$ cell infiltration, including, macrophages, eosinophils and plasma cells [25]. In this context, it has been reported that renal failure occurs in approximately $1 \%-2 \%$ of patients with overdoses of APAP [26]. Acute renal toxicity caused by the drug is characterized by cellular damage initially located in the proximal tubule [27]. Although the molecular mechanisms of acute renal damage caused by APAP have been little studied, have been identified the involvement of oxidative stress and tumoral necrosis factor-alpha (TNF- $\alpha$ ) in this condition [28]. Regarding the results of this work, in vitro studies found that antibiotics antimycin and ionomycin induces proximal tubules damage in rabbit, producing $\mathrm{Ca}^{++}$-induced cytoskeleton alterations, actin redistribution and loss of microvilli on apical membranes of proximal cells; in addition, when proximal tubules were simultaneously exposed to antimycin and ionomycin, cytoskeleton disruption was greater and faster [29]. It should be noted that damage of cytoskeleton and redistribution of actin in proximal cells produced by APAP (and other drugs) are of toxicological significance in early stages of acute kidney injury, as has been reported in patients with nephropathy and in health people, administration of $2 \mathrm{~g}$ of APAP (single dose) did not increase urinary excretion of some damage markers of the brush border membrane and proximal cell lysosomes as is aminopeptidase, dipeptidylpeptidase-IV, $\gamma$-glutamyl and N-acetyl-beta-D-glucosaminidase [30]. Finally, renal damage caused by APAP has been frequently reported, including renal failure [31]. According to the
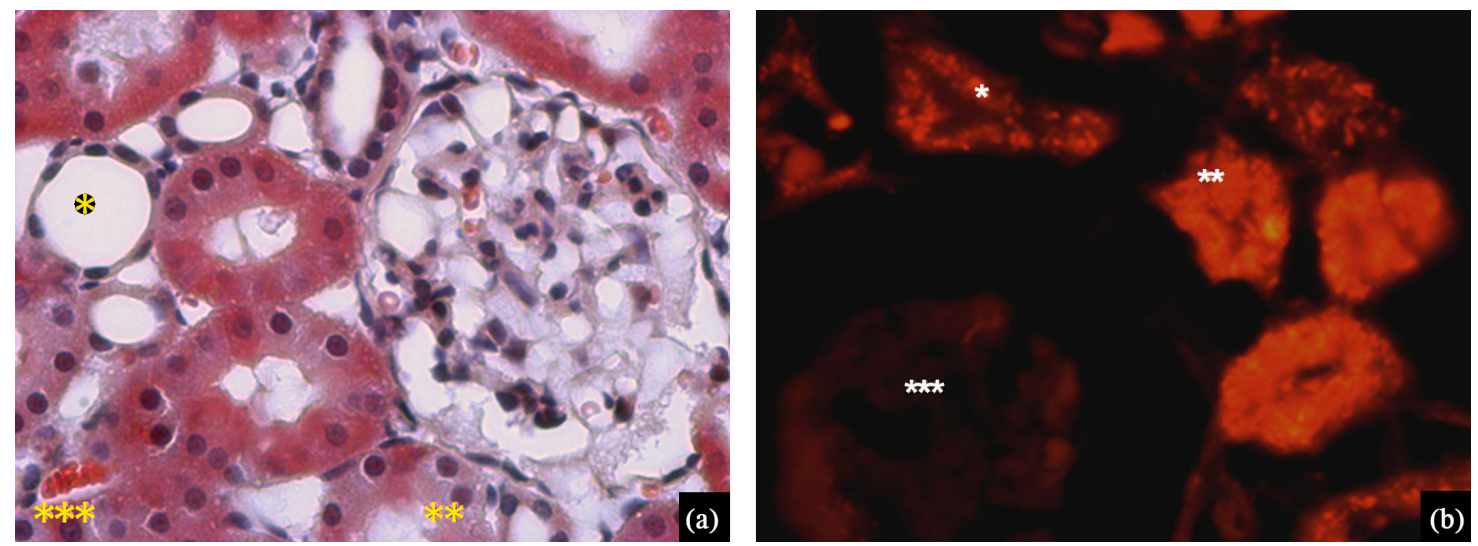

Figure 4. (a) H/E staining renal cortex of rat treated with $1000 \mathrm{mg} / \mathrm{kg}$ of APAP original objective 40X. Picture shows regenerating tubular epithelium $(*)$, tumefaction tubular cells $(* *)$ and necrosis $(* * *)$. (b) Renal cortex of rat treated with 1000 $\mathrm{mg} / \mathrm{kg}$ of APAP labeled with Alexa 594 phalloidin, original objective 40X. Tissue displays regenerating proximal tubular epithelium (*), necrosis (**) and renal glomeruli $(* * *)$. 
results of this work, the damage caused by APAP produce detachment of basement membrane of epithelial cells, cell necrosis as well as changes in F-actin structure [32]. Further studies should be made to elucidate the mechanisms those cause this breakdown.

\section{Conclusion}

APAP administration produced mortality related with doses, thus $100 \%$ was observed in animals that received $1500 \mathrm{mg} / \mathrm{kg}$, and 33.3\% in rats that received $1000 \mathrm{mg} / \mathrm{kg}$ of the drug. At cellular level, APAP produced several morphological damages in kidney, which included tumefaction, detachment of basement membrane and necrosis of proximal tubular epithelium. Tubular epithelial damage interestingly was increased in a dose-dependent, being greater at the dose of $1000 \mathrm{mg} / \mathrm{kg}$ of APAP. This drug induced changes in amount and distribution of F-actin in cells of proximal tubule epithelium, apparently lack of hemidesmosomes zone and disintegration of filamentous actin in the microvilli. These changes were evident in cells with tumefaction and necrosis. More studies are needed to know the damage mechanisms that induced the cytoskeletal changes.

\section{Acknowledgements}

This project was supported by the grant FOMIX-AGS-2005-01-15050 and by Mini-project Support of Basic Sciences Center of Universidad Autonoma de Aguascalientes 2006. JRMP thanks CONACYT for his postdoctoral fellowship.

\section{References}

[1] Mohler, C.R., et al. (2000) Prospective Evaluation of Mild to Moderate Pediatric Acetaminophen Exposures. Annals of Emergency Medicine, 35, 239-244. http://dx.doi.org/10.1016/S0196-0644(00)70074-6

[2] Liliana, C., Mancipe, D.C., Fernández, A., Daniel, G. and Fernández, A. (2010) Acetaminophen Poisoning (Intoxicación por acetaminofén). Revista Med, 18, 221-227. http://dx.doi.org/10.18359/rmed.1314 http://www.scielo.org.co/scielo.php?script=sci_arttext\&pid=S0121-52562010000200008

[3] Ruepp, S.U., et al. (2002) Genomics and Proteomics Analysis of Acetaminophen Toxicity in Mouse Liver. Toxicological Sciences, 65, 135-150. http://dx.doi.org/10.1093/toxsci/65.1.135

[4] Kim, S.J., et al. (2009) Alteration in Metabolism and Toxicity of Acetaminophen upon Repeated Administration in Rats. Journal of Pharmaceutical Sciences, 111, 175-181. http://dx.doi.org/10.1254/jphs.09151FP

[5] Merrill, G.F., et al. (2004) Acetaminophen and Myocardial Infarction in Dogs. The American Journal of PhysiologyHeart and Circulatory Physiology, 287, H1913-H1920. http://dx.doi.org/10.1152/ajpheart.00565.2004

[6] Moyer, A.M., et al. (2011) Acetaminophen-NAPQI Hepatotoxicity: A Cell Line Model System Genome-Wide Association Study. Toxicological Sciences, 120, 33-41. http://dx.doi.org/10.1093/toxsci/kfq375

[7] Koo, E.W., et al. (1987) Aflatoxin B1 and Acetaminophen Induce Different Cytoskeletal Responses during Prelethal Hepatocyte Injury. Experimental and Molecular Pathology, 47, 37-47. http://dx.doi.org/10.1016/0014-4800(87)90005-0

[8] Bajt, M.L., et al. (2004) Acetaminophen-Induced Oxidant Stress and Cell Injury in Cultured Mouse Hepatocytes: Protection by N-Acetyl Cysteine. Toxicological Sciences, 80, 343-349. http://dx.doi.org/10.1093/toxsci/kfh151

[9] Bae, M.A., Pie, J.E. and Song, B.J. (2001) Acetaminophen Induces Apoptosis of C6 Glioma Cells by Activating the c-Jun NH(2)-Terminal Protein Kinase-Related Cell Death Pathway. Molecular Pharmacology, 60, 847-856.

[10] Lorz, C., et al. (2005) Role of Bcl-xL in Paracetamol-Induced Tubular Epithelial Cell Death. Kidney International, 67, 592-601. http://dx.doi.org/10.1111/j.1523-1755.2005.67115.x

[11] Larsson, L., Aperia, A. and Elinder, G. (1983) Structural and Functional Development of the Nephron. Acta Paediatrica Scandinavica Supplement, 305, 56-60. http://dx.doi.org/10.1111/j.1651-2227.1983.tb09860.x

[12] Berry, C.A. and Rector Jr., F.C. (1991) Mechanism of Proximal NaCl Reabsorption in the Proximal Tubule of the Mammalian Kidney. Seminars in Nephrology, 11, 86-97. http://www.ncbi.nlm.nih.gov/pubmed/2034928

[13] Figueiredo, J.F., Bertels, I.M. and Gontijo, J.A. (2008) Actin Cytoskeletal and Functional Studies of the Proximal Convoluted Tubules after Preservation. Transplantation Proceedings, 40, 3311-3315. http://dx.doi.org/10.1016/j.transproceed.2008.06.060

[14] Mariel-Cardenas, J.M.-S., Jaramillo-Juarez, M.C., Rodríguez-Vázquez, F., Gutiérrez-Cantú, M.L., Posadas, F.J. and Guerrero-Barrera, A.L. (2010) Efecto protector del Ginkgo biloba en el daño inducido por paratión metílico en células de la capa granulosa de cerebelo en rata. Rev mex cienc farm, 41, 37-42. 
http://www.redalyc.org/html/579/57916060005/

[15] Prophet, E.B., Mills, B., Arrington, J.B. and Sobin, L.H. (1992) Laboratory Methods in Histotechnology (Armed Forces Institute of Phatology). American Registry of Pathology, Washington.

[16] Guerrero-Barrera, A.L., et al. (1996) Actin-Related Proteins in Anabaena spp. and Escherichia coli. Microbiology, 142, 1133-1140. http://dx.doi.org/10.1099/13500872-142-5-1133

[17] Litjens, S.H., et al. (2003) Specificity of Binding of the Plectin Actin-Binding Domain to Beta4 Integrin. Molecular Biology of the Cell, 14, 4039-4050. http://dx.doi.org/10.1091/mbc.E03-05-0268

[18] Pokutta, S. and Weis, W.I. (2007) Structure and Mechanism of Cadherins and Catenins in Cell-Cell Contacts. Annual Review of Cell and Developmental Biology, 23, 237-261. http://dx.doi.org/10.1146/annurev.cellbio.22.010305.104241

[19] Navarro-Moreno, L.G., et al. (2009) Effects of Lead Intoxication on Intercellular Junctions and Biochemical Alterations of the Renal Proximal Tubule Cells. Toxicology in Vitro, 23, 1298-1304. http://dx.doi.org/10.1016/j.tiv.2009.07.020

[20] Newsome, P.N., et al. (2010) Development of an Invasively Monitored Porcine Model of Acetaminophen-Induced Acute Liver Failure. BMC Gastroenterology, 10, 34. http://dx.doi.org/10.1186/1471-230X-10-34

[21] Dawson, P.A., et al. (2010) Urolithiasis and Hepatotoxicity Are Linked to the Anion Transporter Sat1 in Mice. The Journal of Clinical Investigation, 120, 706-712. http://dx.doi.org/10.1172/JCI31474

[22] Lim, A.Y., Segarra, I., Chakravarthi, S., Akram, S. and Judson, J.P. (2010) Histopathology and Biochemistry Analysis of the Interaction between Sunitinib and Paracetamol in Mice. BMC Pharmacology, 10, 14. http://dx.doi.org/10.1186/1471-2210-10-14

[23] Badmann, A., Keough, A., Kaufmann, T., Bouillet, P., Brunner, T. and Corazza, N. (2011) Role of TRAIL and the Pro-Apoptotic Bcl-2 Homolog Bim in Acetaminophen-Induced Liver Damage. Cell Death and Disease, 2, e171. http://dx.doi.org/10.1038/cddis.2011.55

[24] Boutaud, O., et al. (2010) Acetaminophen Inhibits Hemoprotein-Catalyzed Lipid Peroxidation and Attenuates Rhabdomyolysis-Induced Renal Failure. Proceedings of the National Academy of Sciences of the United States of America, 107, 2699-2704. http://dx.doi.org/10.1073/pnas.0910174107

[25] Fruchter, L.L., Alexopoulou, I. and Lau, K.K. (2011) Acute Interstitial Nephritis with Acetaminophen and Alcohol Intoxication. Italian Journal of Pediatrics, 37, 17. http://dx.doi.org/10.1186/1824-7288-37-17

[26] Mazer, M. and Perrone, J. (2008) Acetaminophen-Induced Nephrotoxicity: Pathophysiology, Clinical Manifestations, and Management. Journal of Medical Toxicology, 4, 2-6. http://dx.doi.org/10.1007/BF03160941

[27] Blantz, R.C. (1996) Acetaminophen: Acute and Chronic Effects on Renal Function. American Journal of Kidney Diseases, 28, S3-S6. http://dx.doi.org/10.1016/S0272-6386(96)90561-2

[28] Ghosh, J., Das, J., Manna, P. and Sil, P.C. (2010) Acetaminophen Induced Renal Injury via Oxidative Stress and TNF-Alpha Production: Therapeutic Potential of Arjunolic Acid. Toxicology, 268, 8-18. http://dx.doi.org/10.1016/j.tox.2009.11.011

[29] Nurko, S., et al. (1996) Contribution of Actin Cytoskeletal Alterations to ATP Depletion and Calcium-Induced Proximal Tubule Cell Injury. American Journal of Physiology, 270, F39-F52. http://www.ncbi.nlm.nih.gov/pubmed/8769821

[30] Mitic-Zlatkovic, M. and Stefanovic, V. (1999) Acute Effects of Acetaminophen on Renal Function and Urinary Excretion of Some Proteins and Enzymes in Patients with Kidney Disease. Renal Failure, 21, 525-532. http://dx.doi.org/10.3109/08860229909045192

[31] Kwok, K.L., Fu, Y.M. and Ng, D.K. (2004) Hepatotoxicity and Persistent Renal Insufficiency after Repeated Supratherapeutic Paracetamol Ingestion in a Chinese Boy. Hong Kong Medical Journal, 10, 61-64. http://www.ncbi.nlm.nih.gov/pubmed/14967859

[32] Dos Remedios, C.G., et al. (2003) Actin Binding Proteins: Regulation of Cytoskeletal Microfilaments. Physiological Reviews, 83, 433-473. http://dx.doi.org/10.1152/physrev.00026.2002 


\section{Submit or recommend next manuscript to SCIRP and we will provide best service for you:}

Accepting pre-submission inquiries through Email, Facebook, LinkedIn, Twitter, etc.

A wide selection of journals (inclusive of 9 subjects, more than 200 journals)

Providing 24-hour high-quality service

User-friendly online submission system

Fair and swift peer-review system

Efficient typesetting and proofreading procedure

Display of the result of downloads and visits, as well as the number of cited articles

Maximum dissemination of your research work

Submit your manuscript at: http://papersubmission.scirp.org/ 